\section{Ms. A.M. Taylor, et al reply}

To the Editor:

We thank Drs. Ruan and Kaye for their comments ${ }^{1}$ on our paper ${ }^{2}$. The topic is important, so further debate over what chronic pain (CP) is helps to refine our thinking.

Voting was undertaken using a computerized, button-press system and the responses were therefore accurately recorded. Rather than being surprised at the $9 \%$ response rate that CP is a "disease," we felt that the $31 \%$ who responded "none of the above" was more puzzling. On reflection, it may be that the cases presented around what CP actually is could have been stronger or that it was a relatively new concept to ask participants to change their existing opinion that $\mathrm{CP}$ is a symptom, to one that embraces pain as a disease, and hence participants were left wanting more information before they decided. As you have correctly suggested, the response may also reflect how "disease" was defined. A "blanket" definition of CP as a disease may also not be appropriate and the definition may depend on the CP condition. Indeed, in someone with new-onset rheumatoid arthritis, for instance, pain could be seen as a symptom of this condition and managing the condition may lead to the symptom of pain being reduced. However, in chronic low back pain, the individual may have large psychosocial issues mediating the pain experience, and the lack of a specific diagnosis and the chronic nature of the experience may render this as a disease. This supports your contentions that persistent pain is multifaceted and can be regarded as having different effects on individuals, and may be related to different rates of progression and the effect that the pain has on function, mood, lifestyle, etc. We agree that there is a spectrum in which persistent pain could range from being a symptom of a disease to a disease in itself depending on its effect and peripheral and central neuroplasticity.

The term "longterm condition (LTC)" was used because in the United Kingdom, the British Pain Society, the Chronic Pain Policy Coalition, Pain $\mathrm{UK}$, and other $\mathrm{CP}$ organizations have worked hard to raise the profile of those living with or experiencing chronic and persistent pain. Having persistent pain mandated as an LTC meant that services for persistent pain could become more equitable to those for other LTC and would no longer be dismissed as a symptom. In 2008 , the Welsh government accepted that persistent pain was an LTC, and this was followed by other countries within the United Kingdom. The consideration in the United Kingdom that pain is an LTC should mean that those living with persistent pain are managed using multidisciplinary models of care and that most management centers around community and primary care, and as with other LTC, still have access to specialist multidisciplinary teams.

We agree that it is important to define persistent pain in a scientific yet practical way, but do not agree that biological measures have had almost no effect on psychiatric practice. Neuroscience has made a number of contributions using functional magnetic resonance imaging techniques and brain markers for diagnosis in a number of psychiatric conditions $s^{3,4,5,6}$. However, as you state, there exists a large body of evidence now illustrating peripheral and central neuroplastic reorganization underlying the disease of $\mathrm{CP}$, which is influenced by biopsychosocial factors.

There are advantages for using the "multifaceted disease" model of persistent pain, as you rightly address. Seeing persistent pain as an LTC and/or a disease is a relatively new concept and conversations such as these help to encourage clinicians to think holistically about the individual living with persistent pain, rather than regarding pain as a symptom that needs to be medically managed with, for example, drug therapy. We applaud the final sentence in your letter: we should do anything within our power to help those living with persistent pain. We add to this power, the importance of shared decision making and evidence-based practice.

ANN M. TAYLOR, PhD, Cardiff University, Cardiff, UK; JUSTIN O. TAYLOR, BSc, Barry Chiropractic Clinic, Cardiff, UK; JASVINDER A. SINGH, MBBS, MPH, Medicine Service, VA Medical Center, Department of Medicine at the School of Medicine, and Division of Epidemiology at the School of Public Health, University of Alabama at Birmingham, and Department of Orthopedic Surgery, Mayo Clinic College of Medicine, Birmingham, Alabama, USA; PHILIP G. CONAGHAN, MBBS, PhD, Leeds Institute of Rheumatic and Musculoskeletal Medicine, University of Leeds and UK National Institute for Health Research Leeds Musculoskeletal Biomedical Research Unit, Leeds, UK; ERNEST H. CHOY, MD, FRCP, Cardiff University, Cardiff, UK; PETER S. TUGWELL, MD, MSc, FRCPC, Department of Medicine, University of Ottawa, Ottawa, Ontario, Canada; ULRIKE KAISER, Dr. rer. Nat. Dipl-Psych, University Hospital Carl Gustav Carus, Dresden, Germany; VIBEKE STRAND, Division of Immunology/Rheumatology, Stanford University, Palo Alto, California, USA; LEE S. SIMON, MD, SDG LLC, Cambridge, Massachusetts, USA; PHILIP J. MEASE, MD, Swedish Medical Center and University of Washington, Seattle, Washington, USA. Address correspondence to Dr. A.M. Taylor, Centre for Medical Education, Cardiff University, Heath Park Site, Cardiff CF14 4XN, UK. E-mail: TaylorAM@ cardiff.ac.uk

\section{REFERENCES}

1. Ruan X, Kaye AD. Defining chronic pain. J Rheumatol 2016; 43:826.

2. Taylor AM, Phillips K, Taylor JO, Singh JA, Conaghan PG, Choy $\mathrm{EH}$, et al. Is chronic pain a disease in its own right? Discussions from a pre-OMERACT 2014 workshop on chronic pain. J Rheumatol 2015;42:1947-53.

3. Bleich-Cohen M, Jamshy S, Sharon H, Weizman R, Intrator N, Poyurovsky M, et al. Machine learning fMRI classifier delineates subgroups of schizophrenia patients. Schizophr Res 2014; 160:196-200

4. Agarwal N, Port JD, Bazzocchi M, Renshaw PF. Update on the use of MR for assessment and diagnosis of psychiatric diseases. Radiology 2010;255:23-41.

5. Koutsouleris N, Meisenzahl EM, Davatzikos C, Bottlender R, Frodl $\mathrm{T}$, Scheuerecker J, et al. Use of neuroanatomical pattern classification to identify subjects in at-risk mental states of psychosis and predict disease transition. Arch Gen Psychiatry 2009;66:700-12.

6. Fu CH, Mourao-Miranda J, Costafreda SG, Khanna A, Marquand AF, Williams SC, et al. Pattern classification of sad facial processing: toward the development of neurobiological markers in depression. Biol Psychiatry 2008;63:656-62.

J Rheumatol 2016;43:4; doi:10.3899/jrheum.151456 